\title{
A novel dermo-cosmetic product containing thermal spring water, sucralfate, copper sulfate, and zinc sulfate in the management of hand
} eczema

This article was published in the following Dove Press journal:

Clinical, Cosmetic and Investigational Dermatology

\author{
Virginie Ribet ${ }^{1}$ \\ Ewa Mielewczyk ${ }^{2}$ \\ Anne Sirvent ${ }^{3}$ \\ Victor Georgescu ${ }^{4}$ \\ Ana Beatris Rossi' \\ 'Clinical Development Department, \\ Pierre Fabre Dermo-Cosmetics, \\ Toulouse, France; ${ }^{2}$ Dermscan \\ Poland Sp. z.o.o., Gdańsk, Poland; \\ ${ }^{3}$ Pharmascan-Dermscan Group, \\ Villeurbanne, France; ${ }^{4}$ Medical \\ Department, Laboratoires \\ Dermatologiques Avène, Lavaur, \\ France
}

\begin{abstract}
Background: The regular use of cosmetic products plays a role in the management of hand eczema (HE) and aids in improving barrier function reducing dryness, roughness, pruritus and improving quality of life (QoL). The aim of this open-label study was to assess the efficacy and the reparative effect of a dermo-cosmetic product on subjects suffering from HE after 7 and 21 days of daily application.
\end{abstract}

Methods: The product was a water-in-oil (W/O) emulsion containing the active ingredients Avène thermal spring water, sucralfate, and copper and zinc sulfates. In total, 32 subjects suffering from either contact dermatitis or climatic dermatitis participated in the trial. The modified total lesion symptom score and physician global assessment scores were used to describe the severity of HE. The safety of the product was assessed through clinical scoring. The subjective tolerance, and acceptance, were documented using a self-assessment questionnaire completed by the subjects. The impact of the dermatosis on QoL was evaluated using the Dermatology Life Quality Index. Results: After 7 days of application, both the physician and subjects noticed a significant improvement in HE. The formula was very well tolerated and accepted. These benefits were correlated with a significant improvement in QoL.

Conclusion: The W/O emulsion used in this study demonstrated real benefits for the subjects suffering from contact dermatitis and climatic dermatitis.

Keywords: climatic/irritant/occupational hand dermatitis, hand eczema, repairing barrier cream, healing dermo-cosmetic, sucralfate, thermal water

\section{Introduction}

Erythema, lichenification, scaling, and fissures accompanied by pruritus and/or pain sensations are some of the symptoms of hand eczema (HE). HE is the most common skin disorder affecting the hands, and its etiology can be very complex. Notably, various clinical signs and affected areas (fingertips, fingers, palm, dorsal hand, and wrist) can coexist in the same patient or can even succeed each over time. ${ }^{1}$ Suggested classifications are based on morphological features associated with etiopathological factors. ${ }^{2,3}$ In 2010, the European Environmental and Contact Dermatitis Research Group $(\text { EECDRG })^{4}$ proposed a classification that identifies seven subdiagnostic groups based on demographic data, medical history, and morphology: allergic contact dermatitis (ACD), irritant contact dermatitis (ICD), ACD + ICD, atopic hand eczema (AHE), AHE + ICD, vesicular dermatitis, and hyperkeratotic dermatitis. According to the EECDRG, ICD is the most frequent (21.5\%), followed by ACD (15.2\%) and the ACD + ICD combination (15.2\%).
Correspondence: Virginie Ribet

Pierre Fabre Dermo-Cosmétique,

Clinical Development Department, 2 rue

Viguerie, BP307I, 31025 Toulouse Cedex

3 , France

Tel +33562488594

Fax +33562488507

Email virginie.ribet@pierre-fabre.com 
The benefits of barrier creams in the treatment of HE have been investigated in numerous studies that have highlighted the importance of maintaining optimal epidermal barrier function even when the skin is clear in HE. Moisturizing creams were shown to prevent flares and reduce the need for topical corticosteroids. ${ }^{5-11}$

The aim of this study was to evaluate the potential of a novel dermo-cosmetic product containing thermal spring water (TSW), sucralfate, copper sulfate, and zinc sulfate in the management of HE. These ingredients were specifically selected for their potential benefits.

Avène TSW is low-mineral-content water $(266 \mathrm{mg} / \mathrm{L})$ that is characterized by a significant amount of silicates, a low sodium concentration, a calcium/magnesium ratio of $1: 2$, and a high diversity of trace elements. This water is particularly soft and suitable for sensitive skins. Hydrotherapy in Avène (France) is prescribed for atopic dermatitis and psoriasis relief, with clear improvements in patients' quality of life (QoL). ${ }^{12,13}$ In vitro studies have demonstrated that Avène TSW presents antiradical and anti-inflammatory properties on keratinocytes ${ }^{14}$ and that it reduces the expression of adhesion molecules on endothelial cells. ${ }^{15}$ Avène TSW decreased IL-8 production and colonization by Staphylococcus aureus ${ }^{16}$ and stimulated keratinocyte differentiation. ${ }^{17}$ The safety and skin recovery efficacy of Avène TSW were confirmed when applied after several dermatological procedures. ${ }^{18-20}$

Sucralfate is a complex salt of sucrose octasulfate and aluminum hydroxide. It was developed in the 1980s for the treatment of acid peptic disease..$^{21}$ It was later shown to have bacteriostatic properties, ${ }^{22}$ to stimulate angiogenesi ${ }^{23}$ and healing. ${ }^{24,25}$ It was successfully used to prevent acute radiation dermatitis of the skin ${ }^{26,27}$ and to treat second- and third-degree burns. ${ }^{28}$ The presence of sucralfate in the present formula favors the recovery of cracks and fissures.

The association of $\mathrm{Cu}-\mathrm{Zn}$ salts prevents bacterial proliferation on the skin. This bacteriostatic action is reinforced by Avène $\mathrm{TSW}^{16}$ and sucralfate. ${ }^{22}$ Limiting microorganism contamination is particularly important in the context of damaged hands: total bacterial counts were shown to be higher as skin damage increased. ${ }^{29,30}$ Skin cleansing participates in preventing infection and $\mathrm{ACD} .{ }^{31}$

\section{Materials and methods}

\section{Clinical protocol}

This open-label study sought to assess tolerance, as a primary objective, and, as a secondary objective, to evaluate the reparative effect of a dermo-cosmetic product applied at least twice daily for 3 weeks on subjects suffering from irritant
HE. The study took place between the end of winter and the beginning of spring in Gdansk, Poland. It was conducted in accordance with the Helsinki Declaration of 1975 and its successive updates. The study was also in compliance with Good Clinical Practices.

The European Directive 2001/20/CE transposed in Polish Law (version of 07.08.2009) was not applicable. Therefore, this study was considered noninterventional and did not require ethics committee approval or competent authority authorization.

\section{Subjects}

The planned number of subjects (male and female) to be analyzed was 30 to minimum 20 subjects with ICD (with ICD resulting from housework, cleaning products, repeated washing, gardening, etc...) and minimum 10 subjects with dermatitis due to physical climatic conditions.

To participate in this study, subjects had to be $>18$ years old and had to present irritated and/or damaged hands, and if possible dry, chapped, and cracked hands. A medical examination with a total minimum modified Total Lesion Symptom Score (mTLSS) of 3 and with a minimum erythema score of 1 was required to be included in the study.

Subjects with confirmed allergic contact eczema or atopic dermatitis were excluded, as well as pregnant or nursing women. The use of any topical or systemic treatment that was likely to interfere with the assessment of the tolerance or efficacy evaluation was exclusionary. Subjects presenting a cutaneous pathology requiring a medical treatment were not accepted. All subjects provided written informed consent prior to participation in the trial.

\section{Product}

The product was a water-in-oil (W/O) emulsion containing Avène TSW (Avène aqua), mineral oil (paraffinum liquidum), myreth-3 myristate, PEG-45/dodecyl glycol copolymer, dimethicone, aluminum sucrose octasulfate, octyldodecanol, PEG-7 glyceryl cocoate, aluminum starch octenylsuccinate, glycerin, beeswax (cera alba), cetyl alcohol, copper sulfate, dimethiconol, disteardimonium hectorite, glyceryl stearate, magnesium sulfate, phenoxyethanol, sodium benzoate, water (aqua), xanthan gum, and zinc sulfate (Cicalfate Hand Cream; Laboratoires Dermatologiques Avène, Lavaur, France)

\section{Trial schedule}

After checking the inclusion and exclusion criteria, baseline hand irritation was scored by the dermatologist using the mTLSS and the Physician's Global Assessment of severity 
(PGA). Standardized macrophotograph of each hand was performed, and the subjects completed the Dermatology Life Quality Index (DLQI) and a subjective questionnaire on the perceived symptoms. The product was issued to the subjects, who had to apply it at least twice daily on the hands for 21 days.

After 7 and 21 days of treatment, the dermatologist performed a new clinical examination of the hands, assessing mTLSS and PGA. Standardized macrophotograph of each hand was performed, the subjects completed the DLQI and the subjective questionnaire on the perceived symptoms and evaluated the reparative effect of the product using the Patient Global Assessment (PaGA) scale. The safety of the product was assessed by the dermatologist. At the end of the treatment, the subjects completed a subjective evaluation questionnaire.

\section{Evaluation tools mTLSS}

This is a composite measure of the intensity of seven individual HE signs or symptoms: erythema, edema, pruritus/ pain, scaling, fissures, hyperkeratosis/lichenification, and vesicles (see Table 1). Each sign is rated on a 4-point scale (from 0 to 3), with the mTLSS calculated as the sum of assigned individual scores. A minimum value of 0 reflects no disease, and a maximum value of 21 corresponds to the most severe disease.

\section{PGA}

This measure assesses disease severity and enables the appreciation of the repairing effect of the product after 7 and 21 days of use (see Table 2). HE severity is rated on a 5-point scale (from $0=$ "clear" to $4=$ "severe").

\section{PaGA}

The repairing effect of the product was evaluated by the subjects using the following scale: $0=$ "clear or almost clear", $1=$ "marked improvement", 2 = "moderate improvement", $3=$ "mild improvement", 4= "no change", and 5= "worsening".

\section{Subjective questionnaire on symptoms}

The subjects recorded their sensations of tightness, stinging, itching, pain, warm, and burning sensations, and others on a 5 -point scale (from $0=$ "none" to $4=$ "severe"). The sum represented the total subjective symptom score that could range from 0 to 28 .

Table I The modified Total Lesion Symptom Score

\begin{tabular}{|c|c|}
\hline \multirow[t]{4}{*}{ Erythema } & $0=\mathrm{absent}$ \\
\hline & $I=$ faint erythema \\
\hline & $2=$ prominent redness \\
\hline & $3=$ deep intense red color \\
\hline \multirow[t]{4}{*}{ Scaling } & $0=$ absent \\
\hline & $\mathrm{I}=$ slight flaking over limited areas, mostly fine scales \\
\hline & $2=$ flaking over widespread area(s), coarser scales \\
\hline & $3=$ desquamation covering over $30 \%$ of the hand, with coarse thick scales \\
\hline \multirow[t]{4}{*}{ Lichenification/hyperkeratosis } & $0=$ absent \\
\hline & $\mathrm{I}=$ mild thickening with exaggerated skin lines over limited areas \\
\hline & $2=$ palpable thickening over widespread area(s) \\
\hline & $3=$ prominent thickening over widespread area(s) with exaggeration of normal skin markings \\
\hline \multirow[t]{4}{*}{ Vesiculation } & $0=$ absent \\
\hline & $\mathrm{I}=$ scattered vesicles affecting up to $10 \%$ of the hand, without erosion \\
\hline & $2=$ scattered or clustered vesicles affecting up to $30 \%$ of the hand, without visible erosion or excoriation \\
\hline & $3=$ high density of vesicles extending over large area(s) or with erosion or excoriation \\
\hline \multirow[t]{4}{*}{ Edema } & $0=$ absent \\
\hline & $\mathrm{I}=$ dermal swelling over $<10 \%$ of the hand \\
\hline & $2=$ definite dermal swelling over $>10 \%$ of the hand \\
\hline & $3=$ dermal swelling with skin induration over widespread area(s) \\
\hline \multirow[t]{4}{*}{ Fissures } & $0=$ absent \\
\hline & $\mathrm{I}=$ cracked skin affecting a small area of the hand \\
\hline & $2=$ cracked skin affecting multiple areas of the hand and causing pain \\
\hline & $3=$ one or more deep fissures causing bleeding or severe pain \\
\hline \multirow[t]{4}{*}{ Pruritus/pain } & $0=$ absent \\
\hline & $\mathrm{I}=$ occasional, slight discomfort a few times per day \\
\hline & $2=$ intermittent, causing discomfort frequently during the day \\
\hline & $3=$ persistent or interfering with sleep \\
\hline
\end{tabular}


Table 2 PGA

\begin{tabular}{|c|c|c|c|}
\hline PGA severity & Features & Intensity & Area involved \\
\hline Severe & Erythema, scaling, hyperkeratosis/lichenification & At least one moderate or severe & $>30 \%$ of affected hand surface \\
\hline (4) & Vesiculation, edema, fissures, pruritus/pain & At least one severe & \\
\hline Moderate & Erythema, scaling, hyperkeratosis/lichenification & At least one mild or moderate & $10 \%-30 \%$ of affected hand \\
\hline (3) & Vesiculation, edema, fissures, pruritus/pain & At least one moderate & surface \\
\hline Mild & Erythema, scaling, hyperkeratosis/lichenification & At least one mild & $<10 \%$ of affected hand surface \\
\hline$(2)$ & Vesiculation, edema, fissures, pruritus/pain & At least one mild & \\
\hline Almost clear & Erythema, scaling, hyperkeratosis/lichenification & At least one mild & $<10 \%$ of affected hand surface \\
\hline (I) & Vesiculation, edema, fissures, pruritus/pain & Absent & \\
\hline Clear & Erythema, scaling, hyperkeratosis/lichenification & Absent & Not detectable \\
\hline$(0)$ & Vesiculation, edema, fissures, pruritus/pain & Absent & \\
\hline
\end{tabular}

Abbreviation: PGA, Physician's Global Assessment.

\section{DLQI}

This instrument evaluates the impact of a dermatological disease on the patient's QoL. It is a 10-question validated questionnaire rating the effect of a dermatosis on social, physical, and functional aspects of life over the last week (from $0=$ "not at all" to $3=$ "very much"). The score varies from 0 (best QoL) to 30 (worst QoL). Scores $<6$ indicate a small impact on the patient's life.

\section{Safety of the product}

Safety was assessed through the documentation of adverse events and a clinical scoring by the dermatologist.

\section{Statistics}

The statistical test applied (Student's $t$-test or Wilcoxon test) was chosen according to the results of the normality test. A type I error of 5\% was chosen (corresponding to the risk of rejecting a true null hypothesis). The software programs used were Excel 10.1 (Microsoft Corporation, Redmond, WA, USA) and SPSS version 17 (IBM, Armonk, NY, USA) statistical software.

\section{Student's $t$-test}

A comparison was performed between the values obtained at baseline (day 0 [D0]) and at the visit at day 7 [D7] and day 21 [D21]. The statistical analysis determined the significance of the measurement variations obtained under the effect of the tested product. The data were analyzed with a paired $t$-test.

\section{Wilcoxon test}

The Wilcoxon sign test was based on the differences between the scores assigned before and after product use, on the same subject, irrespective of the amplitude of these differences. This test compared the number of negative (or positive) differences to the expected value $n / 2$ if $n$ comparisons were made. For all nonparametric tests, if the difference was 0 , the corresponding paired comparisons were discarded from the analysis, and the $\mathrm{n}$ value was consequently reduced.

\section{Results}

Thirty-three subjects were included: 10 men and 23 women with a mean age of 40 years (18-64 years). One subject was lost of follow up after 1 week. Thus, 32 subjects completed the study: 22 with irritant contact dermatitis and 10 with climatic dermatitis. One subject did not answer all of the questions of the DLQI after 1 week, thus invalidating the corresponding data for the DLQI at D7.

\section{mTLSS}

After 7 days of use in the total population, significant improvements in scaling $(-46 \% ; p=0.001)$, pruritus/pain $(-76 \% ; p<0.001)$, and total mTLSS $(-36 \% ; p<0.001)$ were observed on both hands (Figure 1). After 21 days of application, cutaneous signs and symptoms continued to improve: significant decreases in scaling $(-61 \% ; p<0.001)$, pruritus/ pain $(-100 \% ; p<0.001)$, and total mTLSS $(-51 \% ; p<0.001)$ were observed. These benefits were of fast onset for all the subjects with climatic dermatitis (significant decrease in the mTLSS by $39 \%$ at D7; $p<0.001$ ). The best improvement was observed for contact dermatitis subjects after 21 days of use (significant decrease in the mTLSS by $54 \%$ at D21; $p<0.001)$.

\section{PGA}

After 7 days of application, a significant decrease in PGA was observed on both hands in the total population $(-31 \%$; $p<0.001$; Table 3). This lower score reflected symptoms of lower intensity and/or reduced altered areas. After 21 days of application, PGA was reduced by $45 \%$ compared with D0 $(p<0.001)$. The repairing effect was obtained promptly for subjects with climatic dermatitis (PGA decrease by $35 \%$ at 


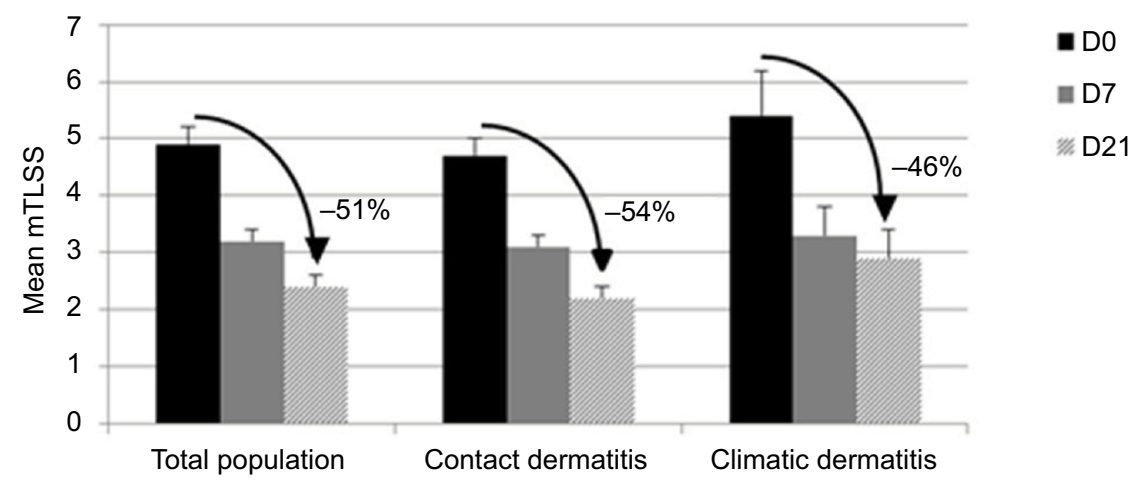

Figure I Reduction in mean mTLSS observed for all subjects, as well as contact and climatic dermatitis subjects. Abbreviations: D0, day 0; D7, day 7; D21, day 21; mTLSS, modified Total Lesion Symptom Score.

Table 3 Mean PGA severity reduction observed on all subjects, as well as contact and climatic dermatitis subjects

\begin{tabular}{llll}
\hline & $\begin{array}{l}\text { Total } \\
\text { population }\end{array}$ & $\begin{array}{l}\text { Contact } \\
\text { dermatitis }\end{array}$ & $\begin{array}{l}\text { Climatic } \\
\text { dermatitis }\end{array}$ \\
\hline$\Delta \%$ Day 7 & $-31 \%$ & $-29 \%$ & $-35 \%$ \\
Significance & $p<0.001$ & $p=0.001$ & $p=0.005$ \\
\hline$\Delta \%$ Day 21 & $-45 \%$ & $-48 \%$ & $-39 \%$ \\
Significance & $p<0.001$ & $p<0.001$ & $p=0.003$ \\
\hline
\end{tabular}

Abbreviation: PGA, Physician's Global Assessment.

$\mathrm{D} 7 ; p=0.001)$, but the maximal benefits were obtained after 3 weeks of treatment on subjects suffering from contact dermatitis (PGA reduction by $48 \% ; p<0.001$ ).

\section{PaGA}

After 1 week of regular application to the hands, $56 \%$ of all subjects noticed a marked improvement in their skin state, and $28 \%$ observed clearing or almost clearing of their symptoms (Figure 2). After 3 weeks of treatment, a change was observed: $66 \%$ of the subjects considered their condition cleared and $22 \%$ noted a marked improvement. The proportion of patients reporting marked improvement of clearance of lesions in the ICD and climatic dermatitis groups were $68 \%$ and $60 \%$ respectively at the end of treatment visit.

\section{Subjective questionnaire on symptoms}

For the total panel, for the contact dermatitis panel, and for the climatic dermatitis panel, the total subjective signs significantly decreased from D7 (respectively, $-73 \%,-66 \%$, and $-92 \%, p<0.05$; Figure 3 ). Notably, tightness sensations were significantly reduced for subjects with contact dermatitis from $-77 \%$ at D7 up to $-93 \%$ on D21 compared with the baseline for contact dermatitis subjects $(p=0.001)$ and from $-78 \%$ at D 7 up to $-95 \%$ at D21 for the total population $(p=0.003$; data not shown).

\section{DLQI}

HE impacted the QoL of all subjects, those suffering from contact dermatitis and climatic dermatitis (Figure 4). After 1 week of regular application of the dermo-cosmetic, the DLQI decreased significantly for both panels $(p<0.001)$. After 21 days of use, QoL was significantly improved for all subjects, irrespective of the origin of the dermatitis $(p<0.001)$. At the end of the study, the mean DLQI was $<2$, showing that the subject's life was no longer impacted by HE.

\section{Cutaneous tolerance}

After 21 days of use, eight subjects presented increase of specific signs scores: four subjects presented crusts and/or erosions due to gardening and four other subjects had cuts and/or erosions due to an injury. These signs were not attributable to the use of the dermo-cosmetic and were judged as not relevant by the dermatologist. Under these study conditions, the product was very well tolerated by all patients.

\section{Cosmetic acceptability}

Overall, the panel acknowledged the cosmetic acceptability of the product: $100 \%$ of the subjects judged the cream to be easy to apply, $91 \%$ noticed rapid absorption, $88 \%$ found that the cream was fading when applying, and $75 \%$ stated that it offered protection as a "second skin." The majority of patients considered that the skin was soothed (85\%), nourished (84\%), repaired $(84 \%)$, and comfortable $(84 \%)$. The skin was not greasy and not sticky (97\%); 93\% observed that the cream soothed discomfort sensations, and $94 \%$ thought that the cream adapted well to sensitive skin. 


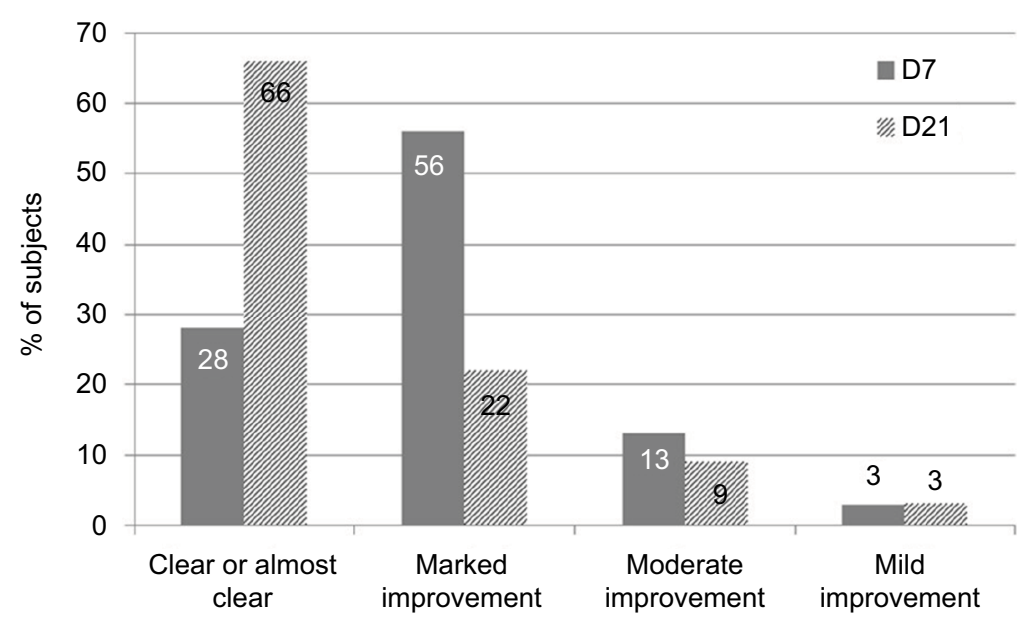

Figure 2 Reparative effect on the total population according to PaGA after 7 or 21 days of daily application of Cicalfate Hand Cream. Abbreviations: D7, day 7; D21, day 21; PaGA, Patient Global Assessment.

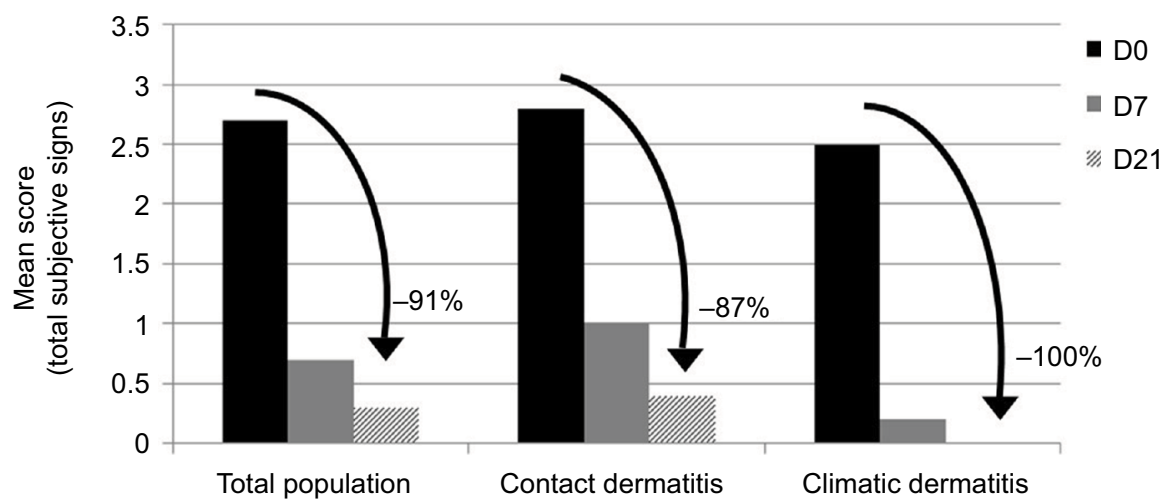

Figure 3 Mean severity score of the total subjective signs reported by the total population, as well as contact and climatic dermatitis subjects. A reduction in the score demonstrates an improvement in the skin condition.

Abbreviations: D0, day 0; D7, day 7; D2I, day 21.

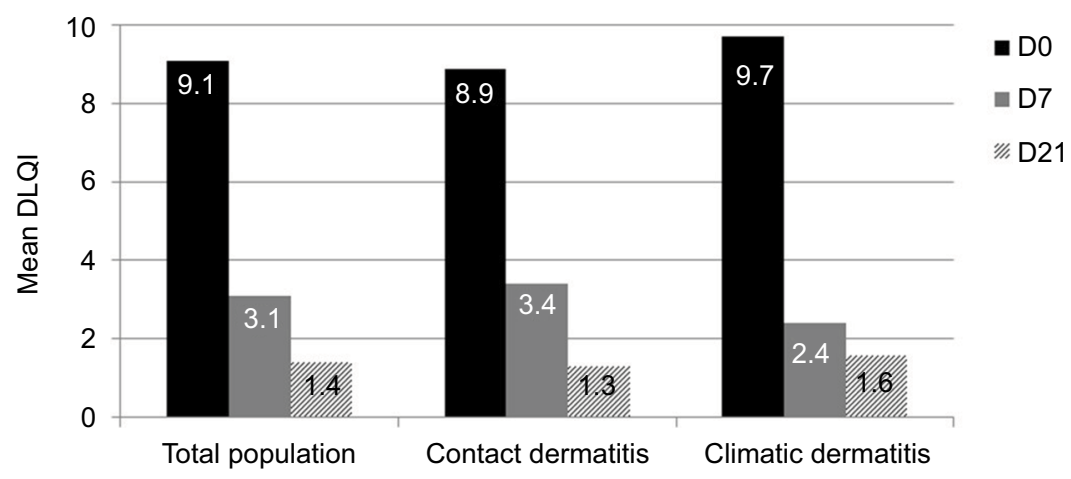

Figure 4 Mean DLQI reduction for the total population, as well as for contact and climatic dermatitis subjects.

Abbreviations: D0, day 0; D7, day 7; D21, day 2I; DLQI, Dermatology Life Quality Index. 


\section{Macrophotographs}

Figures 5 and 6 present the examples of some results.

\section{Discussion}

$\mathrm{HE}$ is a very frequent dermatosis that occurs through numerous endogenous (genetic predisposition, atopic disease, etc) and exogenous factors (harsh climatic conditions, wet work, irritant contact, allergic reactions, etc). The objective and reproducible quantification of $\mathrm{HE}$ is an obligation for clinical trials. Clinical scoring is a well-established practice in dermatology, and several HE severity scores have been proposed based on signs, symptoms, and/or specific locations..$^{32}$ Here, a combination of various modalities was used to assess $\mathrm{HE}$ in subjects suffering from either irritant contact dermatitis (22 subjects) or climatic dermatitis (10 subjects). The PGA score, which was based on categories defined by clinical criteria, was combined using the mTLSS, a quantitative scoring system, and the patient's subjective evaluation.

In this study, an analysis of the mTLSS and PGA scores as well as the PaGA and the subjective symptoms led to the same conclusion: repeated cream applications on hands induced the rapid improvement in climatic dermatitis subjects from D7 and a maximum benefit for contact dermatitis subjects at D21. Interestingly, there was a $100 \%$ reduction in pruritus and pain for the subjects at D21.

If severity scores directly focus on the state of the HE, QoL questionnaires consider other aspects such as feelings, daily activities, and personal relationships. ${ }^{33}$ Several clinical studies highlighted the link between HE occurrence and perceived alterations in the QoL. ${ }^{34-38}$ This condition can be a source of anxiety, low self-esteem, and social phobia. In severe cases, patients find HE is debilitating for leisure activities and/or work, resulting in sick leave and an elevated economic burden..$^{39-42}$ DLQI was designed to measure the disability caused by any skin disease, ${ }^{43}$ and it is often used in clinical practice to evaluate the impact of HE on QoL. A Danish study performed on 564 subjects suffering from HE highlighted the correlation between the severity of skin damage and an alteration in QoL: a DLQI score of 3 was observed in minimal forms, a score of 6 corresponded to moderate forms, and severe forms had a score of $7.8{ }^{44} \mathrm{In}$ the present study, we obtained a mean DLQI score of 9.1 at D0 in the total population. This score reflected suffering due to dermatosis. The fast onset improvement and benefit of the cream observed by both the physician and the subjects induced a real improvement in health-related QoL in all
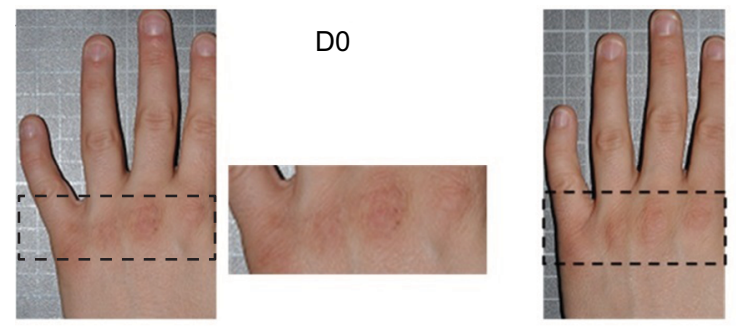

Figure 5 Examples of results observed for a woman suffering from contact dermatitis. Erythema was reduced after 21 days of cream application. Abbreviations: D0, day 0; D2I, day 21.
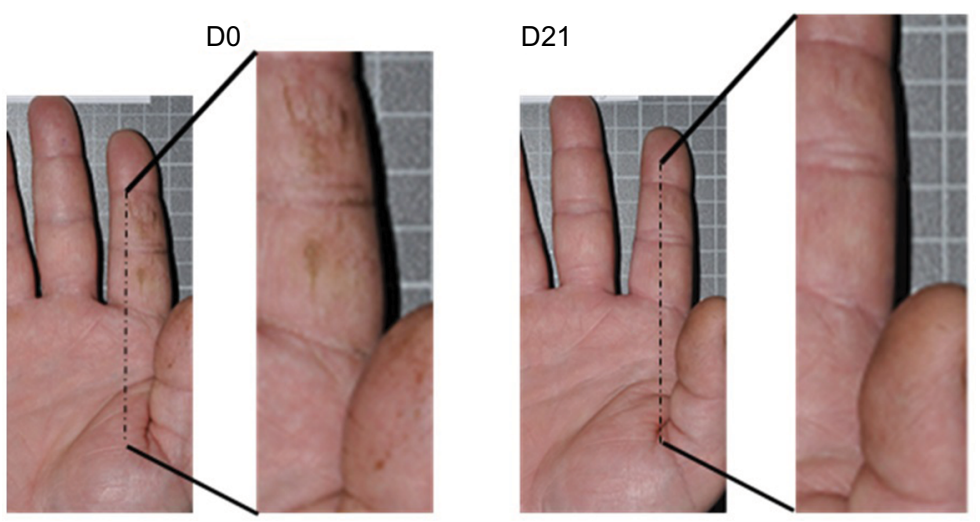

Figure 6 Examples of results observed for a man suffering from climatic dermatitis. Fissures were reduced after $2 \mathrm{I}$ days of cream application. Abbreviations: D0, day 0; D2I, day 21 . 
subjects from D7. This is particularly evident for climatic dermatitis subjects whose mean DLQI decreased to 2.4 at D7. Notably, epidemiological studies suggested that climate influences the prevalence of eczema occurrence. Atopic eczema has been reported worldwide to be negatively associated with temperature..$^{45,46}$

The successes of the treatment observed here are the results of the repairing effects of the formula, which is an emulsion that contains several active ingredients: Avène TSW $64 \%$, sucralfate $3 \%$, copper sulfate $0.1 \%$, and zinc sulfate $0.1 \%$. The good cosmetic acceptability of the product encouraged frequent and diligent applications. The formula was developed to provide a rich skin feeling when applying, which evolves to a light, nonsticky, and silky texture after massage. Subjects used the barrier cream more frequently because the cream was very well tolerated and because discomfort was soothed. Low treatment satisfaction in dermatological patients leads to poor compliance and thus poor treatment outcome. ${ }^{47,48} \mathrm{~A}$ randomized and controlled study performed on metalworkers with occupational HE confirmed the critical importance of application compliance. ${ }^{49}$

Furthermore, the product benefited from extensive clinical evaluations (data not shown). Its safety was objectively assessed by repeated open application tests (ROAT) first on healthy skin, then on damaged skin as well as by the human repeated insult patch test (HRIPT). Cutaneous tolerance was very good in all tests. The efficacy and acceptability of the cream were tested on subjects with sensitive skin on the hands, and the water resistance and reparative character were also demonstrated on sodium lauryl sulfate-damaged skin.

\section{Conclusion}

The W/O emulsion used in this study (Cicalfate Hand Cream) demonstrated real benefits for subjects suffering from irritant contact dermatitis and climatic dermatitis. The original formula was very well tolerated and acceptable to patients. Both physicians and subjects noticed a significant improvement in HE symptoms starting at 7 days after the first application.

\section{Acknowledgments}

This study was funded by Pierre Fabre Dermo-Cosmétique, Toulouse, France. E Mielewczyk was paid as a consultant, and A Sirvent is an employee of the Dermscan group, which is a contract research organization that received funding from Pierre Fabre Laboratories to conduct the study. The authors would like to thank the Dermscan staff who recruited subjects for this study, for their professionalism and support during study development, and Rachida Bahassou-Benamri (paid as a consultant) for writing assistance, as well as editing and proofreading the manuscript.

\section{Disclosure}

V Ribet, V Georgescu, and AB Rossi are employees of Pierre Fabre Laboratories, which markets the test product. The authors report no other conflicts of interest.

\section{References}

1. Halioua B, Richard MA; Groupe d'experts sur l'eczéma chronique des mains. Mise au point sur l'eczéma chronique des mains [Update on chronic hand eczema]. Ann Dermatol Venereol. 2010;137:315-327. French.

2. Cronin E. Clinical patterns of hand eczema in women. Contact Dermatitis. 1985;13:153-161.

3. Agner T. Hand eczema. In: Johansen JD, Frosch PJ, Lepoittevin JP, editors. Contact Dermatitis. $5^{\text {th }}$ ed. Berlin-Heidelberg: Springer-Verlag; 2011:396-406.

4. Thyssen J, Johansen J, Linneberg A, Menné T. The epidemiology of hand eczema in the general population - prevalence and main findings. Contact Dermatitis. 2010;62:75-87.

5. Halkier-Søsensen L, Thesirup-Pedersen K. The efficacy of a moisturizer (Locobase) among cleaners and kitchen assistants during everyday exposure to water and detergents. Contact Dermatitis. 1993;29:266-271.

6. McCormick RD, Buchman TL, Maki DG. Double-blind, randomized trial of scheduled use of a novel barrier cream and an oil-containing lotion for protecting the hands of health care workers. Am J Infect Control. 2000;28:302-310.

7. Berndt U, Wigger-Alberti W, Gabard B, Elsner P. Efficacy of a barrier cream and its vehicle as protective measures against occupational irritant contact dermatitis. Contact Dermatitis. 2000;42,77-80.

8. Held E, Mygind K, Wolff C, Gyntelberg F, Agner T. Prevention of work related skin problems: an intervention study in wet work employees. Occup Environ Med. 2002;59:556-561.

9. Kucharekova M, Van de Kerkhof PC, Van der Valk PG. A randomized comparison of an emollient containing skin-related lipids with a petrolatum-based emollient as adjunct in the treatment of chronic hand dermatitis. Contact Dermatitis. 2003;48:293-299.

10. Mygind K, Sell L, Flyvholm MA, Jepsen KF. High-fat petrolatum-based moisturizers and prevention of work-related skin problems in wet-work occupations. Contact Dermatitis. 2006;54:35-41.

11. Williams C, Wilkinson SM, McShane P, et al. A double-blind, randomized study to assess the effectiveness of different moisturizers in preventing dermatitis induced by hand washing to simulate healthcare use. Br J Dermatol. 2010;162:1088-1092.

12. Taieb C, Sibaud V, Merial-Kieny C. Impact of Avène hydrotherapy on the quality of life of atopic and psoriatic patients. J Eur Acad Dermatol Venereol. 2011;25:24-29.

13. Merial-Kieny C, Mengual X, Guerrero D, Sibaud V. Clinical efficacy of Avène hydrotherapy measured in a large cohort of more than 10,000 atopic or psoriatic patients. J Eur Acad Dermatol Venereol. 2011;25:30-34.

14. Merial-Kieny C, Castex-Rizzi N, Selas B, Mery S, Guerrero, D. Avène Thermal Spring Water: an active component with specific properties. $J$ Eur Acad Dermatol Venereol. 2011;25:2-5.

15. Castex-Rizzi N, Charveron M, Merial-Kieny C. Inhibition of TNF-alpha induced-adhesion molecules by Avène Thermal Spring Water in human endothelial cells. J Eur Acad Dermatol Venereol. 2011;25:6-11.

16. Casas $\mathrm{C}$, Ribet $\mathrm{V}$, Alvarez-Georges $\mathrm{S}$, et al. Modulation of Interleukin-8 and staphylococcal flora by Avène hydrotherapy in patients suffering from chronic inflammatory dermatoses. J Eur Acad Dermatol Venereol. 2011;25:19-23. 
17. Lehen'kyi V, Vandenberghe M, Belaubre F, et al. Acceleration of keratinocyte differentiation by transient receptor potential vanilloid (TRPV6) channel activation. J Eur Acad Dermatol Venereol. 2011;25:12-18.

18. Sulimovic L, Licu D, Ledo E, et al. Efficacy and safety of a topically applied Avène spring water spray in the healing of facial skin after laser resurfacing. Dermatol Surg. 2002;28:415-418.

19. Goldman MP, Merial-Kieny C, Nocera T, Mery S. Comparative benefit of two thermal spring waters after photodynamic therapy procedure. $J$ Cosmet Dermatol. 2007;6:31-35.

20. Barolet D, Lussier I, Mery S, Merial-Kieny C. Beneficial effects of spraying low mineral content thermal spring water after fractional photothermolysis in patients with dermal melasma. J Cosmet Dermatol. 2009;8:114-118.

21. Nagashima R. Development and characteristics of sucralfate. J Clin Gastroenterol. 1981;3:103-110.

22. Tryba M, Mantey-Stiers F. Antibacterial activity of sucralfate in human gastric juice. Am J Med. 1987;83:125-127.

23. Szabo S, Vattay P, Scarbrough E, Folkman J. Role of vascular factors, including angiogenesis, in the mechanisms of action of sucralfate. $\mathrm{Am}$ J Med. 1991;91:158S-160S.

24. Burch RM, McMillan BA. Sucralfate induces proliferation of dermal fibroblasts and keratinocytes in culture and granulation tissue formation in full-thickness skin wounds. Agents Actions. 1991;34:229-231.

25. Shindo K, Iizuka M, Sasaki K, et al. Sucralfate prevents the delay of wound repair in intestinal epithelial cells by hydrogen peroxide through NF-кB pathway. J Gastroenterol. 2006;41:450-461.

26. Maiche A, Isokangas OP, Grohn P. Skin protection by sucralfate cream during electron beam therapy. Acta Oncol. 1994;33:201-203.

27. De Rauglaudre G, Courdi A, Delaby-Chagrin F, et al. Tolérance de 1'association de sucralfate/sels de $\mathrm{Cu}-\mathrm{Zn}$ dans les radiodermites [Tolerance of the association sucralfate/Cu- $\mathrm{Zn}$ salts in radiation dermatitis]. Ann Dermatol Venereol. 2008;1:11-15. French.

28. Banati A, Chowdhury SR, Mazumder S. Topical use of Sucralfate Cream in second and third degree burns. Burns. 2001;27:465-469.

29. Winnefeld M, Richard MA, Drancourt M, Grob JJ. Skin tolerance and effectiveness of two hand decontamination procedures in everyday hospital use. Br J Dermatol. 2000;143:546-550.

30. de Almeida e Borges LF, Silva BL, Gontijo Filho PP. Hand washing: changes in the skin flora. Am J Infect Control. 2007;35:417-420.

31. Bonneville M, Chavagnac C, Vocanson M, et al. Skin contact irritation conditions the development and severity of allergic contact dermatitis. J Invest Dermatol. 2007;127:1430-1435.

32. Weistenhöfer W, Baumeister T, Drexler H, Kütting B. An overview of skin scores used for quantifying hand eczema: a critical update according to the criteria of evidence-based medicine. Br J Dermatol. 2010;162:239-250.

33. Agner T, Jungersted JM, Coenraads PJ, Diepgen T. Comparison of four methods for assessment of severity of hand eczema. Contact Dermatitis. 2013;69:107-111.
34. Cvetkovski RS, Jensen H, Olsen J, Johansen JD, Agner T. Relation between patients' and physicians' severity assessment of occupational hand eczema. Br J Dermatol. 2005;153:596-600.

35. van Coevorden A, van Sonderen E, Bouma J, Coenraads PJ. Assessment of severity of hand eczema: discrepancies between patient- and physician-rated scores. Br J Dermatol. 2006;155:1217-1222.

36. Agner T, Andersen KE, Brandao FM, et al. Hand eczema severity and quality of life: a cross-sectional, multicentre study of hand eczema patients. Contact Dermatitis. 2008;59:43-47.

37. Moberg C, Alderling M, Meding B. Hand eczema and quality of life a population-based study. Br J Dermatol. 2009;161:397-403.

38. Bingefors K, Lindberg M, Isacson D. Quality of life, use of topical medications and socio-economic data in hand eczema: a Swedish nationwide survey. Acta Derm Venereol. 2011;91:452-458.

39. Diepgen TL, Agner T, Aberer W, et al. Management of chronic hand eczema. Contact Dermatitis. 2007;57:203-210.

40. van der Meer EW, Boot CR, van der Gulden JW, Jungbauer FH, Coenraads PJ, Anema JR. Hand eczema among healthcare professionals in the Netherlands: prevalence, absenteeism, and presenteeism. Contact Dermatitis. 2013;69:164-171.

41. Cortesi PA, Scalone L, Belisari A, et al. Cost and quality of life in patients with severe chronic hand eczema refractory to standard therapy with topical potent corticosteroids. Contact Dermatitis. 2013;70:158-168.

42. Elston DM, Ahmed DD, Watsky KL, Schwarzenberg K. Hand dermatitis J Am Acad Dermatol. 2002;47:291-299.

43. Finlay AY, Khan GK. Dermatology Life Quality Index (DLQI) - a simple practical measure for routine clinical use. Clin Exp Dermatol. 1994;19:210-216.

44. Cvetkovski RS, Zachariae R, Jensen H, Olsen J, Johansen JD, Agner T. Quality of life and depression in a population of occupational hand eczema patients. Contact Dermatitis. 2006;54:106-111.

45. Weiland SK, Husing A, Strachan DP, Rzehak P, Pearce N; ISAAC Phase One Study Group. Climate and the prevalence of symptoms of asthma, allergic rhinitis, and atopic eczema in children. Occup Environ Med. 2004;61:609-615.

46. Byremo G, Rød G, Carlsen KH. Effect of climatic change in children with atopic eczema. Allergy. 2006;61:1403-1410.

47. Renzi C, Abeni D, Picardi A, et al. Factors associated with patient satisfaction with care among dermatological outpatients. Br J Dermatol. 2001;145:617-623.

48. Herschel S, Schmitt J, Bauer A. Satisfaction with medical treatment in patients with hand dermatitis - a cross-sectional study. J Dtsch Dermatol Ges. 2013;11:1007-1013.

49. Kütting B, Weistenhöfer W, Baumeister T, Uter W, Drexler H. Current acceptance and implementation of preventive strategies for occupational hand eczema in 1355 metalworkers in Germany. Br J Dermatol. 2009;161:390-396.
Clinical, Cosmetic and Investigational Dermatology

\section{Publish your work in this journal}

Clinical, Cosmetic and Investigational Dermatology is an international, peer-reviewed, open access, online journal that focuses on the latest clinical and experimental research in all aspects of skin disease and cosmetic interventions. This journal is included on PubMed. The manuscript management system is completely online

\section{Dovepress}

and includes a very quick and fair peer-review system, which is all easy to use. Visit http://www.dovepress.com/testimonials.php to read real quotes from published authors 